\title{
LA PROTECCIÓN DEL PATRIMONIO ARQUEOLÓGICO DESDE EL MUSEO II Criterios de Difusión
}

\author{
Concha San Martín Montilla \\ Conservadora del Museo \\ Arqueológico de Sevilla
}

El presente artículo es continuación del publicado en nuestro Boletín Informativo $N^{\circ}$ 7, junio de 1994.
La expresión y explicación del medio y la función originales del objeto constituirían un primer nivel de contextualización, que puede desarrollarse en diferentes grados, en función de la cantidad y calidad de las informaciones del registro arqueológico, del alcance de los estudios realizados y las conclusiones a que lleguen los investigadores.

Pero en muchos museos arqueológicos existe una proporción importante de objetos que no fueron recuperados con metodología arqueológica y que formaron parte de una colección, hasta el ingreso en el museo -o que aún se incluyen en una, si están en el museo en calidad de depósito-. Esto significa una deficiente o nula información sobre su contexto espacial y funcional. La información inherente al objeto: su forma, técnica de fabricación, decoración, etc., pueden ayudar a efectuar, a veces, una limitada contextualización histórica.

Paolo Liverani (1992, 37-39), dentro de lo que él llama la atención privilegiada al contexto, que considera que debe ser el leit motiv de toda la actividad del museo, contempla un segundo nivel de contextualización para este tipo de objetos: el de las colecciones y el coleccionismo. Para el desarrollo de este nivel, en la composición expositiva y en sus elementos, puede sustituirse la relación con el medio original desconocido con aquel o aquellos en que permanecieron, tras su recuperación e inclusión en una colección, antes de ingresar en el museo. La expresión de dicha relación puede igualmente conseguirse con la propia composición y las relaciones entre sus elementos, así como con el recurso a la imagen: antiguos dibujos, documentos originales o fotografías sobre el coleccionista, el ambiente histórico-coleccionista o las anteriores instalaciones de la colección. Los textos explicativos deben contribuir a definir el coleccionismo como una actividad arqueológica del pasado, que hoy puede ser valorada con perspectiva histórica en sus aspectos positivos y negativos, pero que debe terminar, y que su continuidad, gracias al refuerzo proporcionado por el positivismo clásico, sólo ha contribuido y contribuye a la destrucción del patrimonio arqueológico.

La importancia de la difusión contextualizada de los objetos arqueológicos para la consecución de objetivos de protección del patrimonio histórico, se completa con la inclusión del proceso de investigación arqueológica en el discurso de las actividades de difusión. La propia atención al contexto ya ofre- ce un primer nivel de inclusión en la exposición, puesto que el público puede entonces distinguir perfectamente los objetos que han sido recuperados con metodología cientíica y las ventajas que de ello se derivan para el conocimiento histórico y su aprovechamiento cultural, de aquellos que por haber sido recuperados sin el concurso de una investigación científica han perdido la mayor parte o toda la información contextual, y que por ello manifiestan importantes carencias para su interpretación y comprensión.

Centrándonos de nuevo en la exposición, las largas introducciones al método arqueológico de investigación tienen muy poca trascendencia -entre otras cosas porque la mayor parte del público no les presta atención- si luego no tienen una continuación en las salas. En mi opinión, es más efectivo desgranar toda una serie de mensajes reforzados siempre con imágenes en relación directa con el proceso de investigación concreta que afecta a los objetos que el público contempla, consiguiendo que éste valore los procedimientos científicos arqueológicos por los resultados; es decir, por los hechos y no sólo por las palabras.

Respecto a la difusión orientada a la protección del patrimonio arqueológico, la inclusión del proceso de investigación en el discurso expositivo, y en general de cualquier actividad de difusión, debe introducir conceptos que contribuyan a ese objetivo y combatir aquellos que lo perjudican. Citaré algunos que considero básicos:

- Combatir el concepto de que el objetivo exclusivo de la Arqueología es la búsqueda de objetos para su estudio -muy extendido entre el público en general- sustituyéndolo por el del análisis, comprensión y explicación de las sociedades humanas pretéritas a través del estudio de su cultura material, que no se reduce a los objetos, sino que se extiende a un conjunto de manifestaciones mucho más amplio: estructuras constructivas, deshechos de actividades de producción, distribución o consumo, restos paleoambientales, etc., así como asociaciones y relaciones espaciales a varios niveles, en el interior del asentamiento, con su medioambiente circundante $y$ entre asentamientos.

- Combatir la caracterización de la excavación como procedimiento exclusivo de investigación en Arqueología -idea también muy extendida entre un sector importante de la sociedad- e ilustrar sobre 
los distintos procedimientos de investigación que pueden incluirse -pero no necesariamente todosen un proyecto arqueológico.

La combinación de estos dos conceptos equívocos -el objeto como objetivo único de la Arqueología y la excavación como única forma de investigaciónconducen a la idea igualmente errónea de que la única forma de protección del patrimonio arqueológico es la excavación con el fin de salvar los objetos mediante su extracción. Y de ahí, la frecuente reivindicación por parte de la opinión pública de que se excaven los yacimientos para la conservación del patrimonio arqueológico. Es necesario, pues, insistir en la idea de que el yacimiento puede conservarse perfectamente sin necesidad de ser excavado. Que a la excavación se llega sólo, o por exigencias de investigación o por necesidades de equilibrio entre el desarrollo económico y la conservación de los testimonios del pasado, y siempre que se garantice la calidad de la intervención en base a los principios metodológicos que la comunidad científica en general considera imprescindibles.

- Hay que combatir asimismo el concepto de prospección arqueológica como actividad de mera localización de yacimientos potencialmente excavables. Es preciso actualizar este concepto en la difusión, ya que en la investigación arqueológica desde hace más de dos décadas, la prospección ya no se subordina necesariamente a la posterior excavación y posee unos objetivos propios, que pueden ser complementarios de ésta. Mediante la aplicación de los instrumentos analíticos de la llamada Arqueología Espacial, la prospección puede pasar de la visón particular del yacimiento, excavado o no, y sus relaciones espaciales internas, a la visión globalizada de un territorio y la ordenación en el mismo de los diferentes testimonios de las actividades humanas del pasado.Y es muy importante difundir el valor de la prospección como estrategia privilegiada de protección en su aspecto preventivo, puesto que los conocimientos que aporta permiten planificar las intervenciones arqueológicas de una forma más adecuada y armónica con el desarrollo económico, evitando o minimizando los conflictos.

- Por último, y no es que con ello cierre la lista, actualizar el espectro de métodos analíticos que se emplean actualmente en Arqueología, como consecuencia del desarrollo tecnológico, pero también de cambios teóricos y metodológicos que han abierto nuevos objetivos de investigación, más allá de la reconstrucción de la secuencia cronológico-cultural, objetivo único de la arqueología positivista clásica o tradicional. Propongo, pues, la ilustración selectiva, nunca exhaustiva, sobre los análisis específicos efectuados sobre los objetos arqueológicos incluidos en cualquier actividad de difusión, y sobre sus consecuencias en el nivel interpretativo, como son, por ejemplo: los análisis microespaciales para la determinación de áreas de actividades de producción, distribución o consumo; los análisis macroespaciales para definir la ordenación del territorio, los sistemas de captación de recursos, las vías de comunicación, la jerarquización de los asentamientos o el establecimiento de fronteras políticas; los análisis faunísticos y botánicos para la reconstrucción del medioambiente, de las bases de explotación agrícola-ganadera y de la dieta alimenticia; los análisis traceológicos para la determinación de las huellas de uso y, con ello, la funcionalidad de los útiles; la variedad de análisis para determinar la cronología absoluta y un largo etcétera de analíticas especificas. Todo ello, contribuye a reforzar la valoración del contexto de los restos arqueológicos, y del método científico de investigación arqueológica, y en consecuencia la compresión por parte del público de que son valores por defender si queremos conservar eficazmente nuestro patrimonio histórico.

Estas propuestas de criterios se derivan, además de mi experiencia profesional, como dije al principio, de la realidad que personalmente he conocido respecto a las actividades de difusión de muchos museos arqueológicos, especialmente las exposiciones, tanto permanentes como temporales, y las publicaciones, y que resumo de la siguiente manera:

- descontextualización espacial, funcional e histórica; - ausencia del proceso de investigación cientííca;

- equiparación, en el discurso o en las técnicas, expositivas de los objetos procedentes del mercado de antigüedades o del coleccionismo con aquellos recuperados a través de un procedimiento científico, con lo cual éste queda invalidado, al no poder ser valorado y comparado con los procedimientos no cientíícos de recuperación de objetos arqueológicos, que tampoco se incluyen en el discurso;

- interpretaciones monolíticas y sin razonar. Ausencia, pues, de argumentación y alternativas de interpretación, cuando las hay, que permitan al público asimilar que la ciencia genera conclusiones susceptibles de discusión y contestación, y no dogmas de fe;

\section{La importancia}

de la difusión

contextualizada de los

objetos arqueológicos

se completa con la

inclusión del proceso

de investigación

arqueológica

en el discurso de las

actividades

de difusión. 


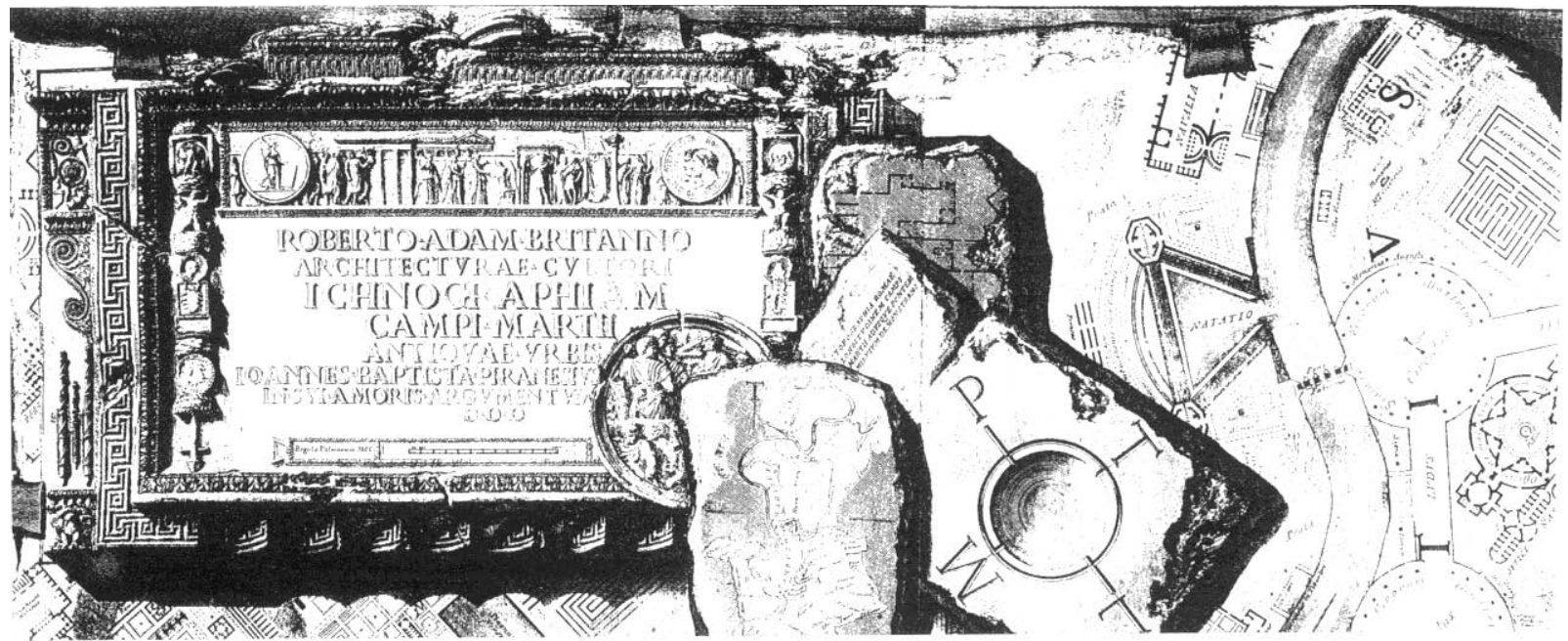

\section{BIBLIOGRAFIA}

Benes.J. 1983. "Variabilidad de los modos de exposición.

Museum $n^{\circ}$ 138. Unesco. París, pp. 102-107.

Chang, K. C. 1976. Nuevas perspectivas en Arqueología. Alianza Editorial.

Madrid (1 ${ }^{a}$ ed. 1967).

García Blanco, A.Asencio Brouard.M., Pol Méndez, E. 1992. "El público y la exposición. ¿Existen dificultades de compresión?”.

Boletín del Museo Arqueológico Nacional. Madrid, pp.93-106.

Liberani, P. 1992. Le raccolte storiche. Eutopía,

$n^{\circ}$ 1. Roma, pp. 35-39.

Ruiz Rodríguez, A., Molinos Molinos, M., Hornos Mata, F. 1986. Arqueología en Jaén Reflexiones desde un proyecto arqueológico no inocente). Diputación Provincial de Jaén.

Sola, T. 1987. Concepto y naturaleza de la museología. Museum $n^{o}$ 153. Unesco. París, pp. 45-49.
- ausencia de diversidad de ofertas y niveles de información, que supone la marginación de determinados sectores de público, generalmente los más mayoritarios, pero también de ciertas minorías sociales o intelectuales. La diversidad de ofertas y de niveles asegura el principio democrático de atención prioritaria a la mayoría dentro de un respeto, y por tanto también atención, a las minorías.

En los museos arqueológicos, esta situación, en parte es consecuencia del comportamiento tradicional del colectivo de los arqueólogos, al destinar el resultado de su investigación exclusivamente "al consumo de colegas y estudiantes". (CHANG, 1976, p. 159). Como dicen RUIZ, MOLINOS Y HORNOS (1986, p. 50) ...'reconoceremos en este punto la parte de responsabilidad que nos cabe a los profesionales de la Arqueología, que por un desinterés, que algunas veces roza el desprecio acerca de estos temas de difusión, caemos en un círculo vicioso o mejor en una trampa que nos atrapa lamentablemente, ya que, al ocultar para proteger o al no atender a la difusión de nuestra investigación, que es en realidad lo que dota a nuestra labor de su más auténtica utilidad social, hemos fomentado una actitud que ha perjudicado enormemente aquello que, en definitiva, constituye la materia prima de nuestro trabajo".

Por otro lado, y esto afecta a todos los tipos de museos, tenemos la ausencia habitual de los profesionales de la pedagogía, psicología o comunicología en el diseño y desarrollo de las actividades de difusión del museo, y especialmente de las exposiciones permanentes y temporales. Aunque el equipo técnico del museo tenga muy claro, y no siempre lo tiene, cual es el mensaje que quiere transmitir y cuales los criterios de difusión, es obvio que no puede hacerlo bien sin el concurso de los especialistas en cómo hacerlos llegar a la totalidad del público y a sus diferentes sectores, y en evaluar si se cumplen o no los objetivos que se propongan.
Como han demostrado GARCÍA BLANCO, ASENSIO Y POL ( 1992) en sus análisis, el empleo de la intuición en el diseño y montaje expositivo se revela como ineficaz, poniendo de manifiesto la necesidad de estudios sistemáticos de evaluación de los aspectos del público. En su trabajo de evaluación cognitiva de la exposición de "Los Bronces Romanos en España", estos autores concluyen que "el nivel de instrucción de los visitantes se conforma como la variable fundamental que condiciona la comprensión de la exposición, muy por encima de variables tradicionalmente consideradas como la edad. Las pruebas de comprensión así como la de activación de conocimiento específico obtuvieron muy altos índices de correlación. Igualmente, las pruebas de conocimiento específico demostraron la existencia de importantes errores previos que pueden estar cortocircuitando la comprensión de la exposición. Sería muy importante poder prever este tipo de errores o concepciones erróneas previas (más aún de cara a las colecciones permanentes), sobre todo porque la exposición debe prever y contar con ellos en su diseño, si queremos superarlos".

Yo creo, y esto es un juicio intuitivo, que existen importantes errores previos entre el público de los museos sobre la Arqueología y los arqueólogos, que inciden negativamente sobre la protección del patrimonio histórico. Pero, sin duda, es hora de desarrollar proyectos de análisis y evaluación similares al citado. Mi propuesta es que en ellos se incluyan los conceptos equivocados a que me he referido en este texto, con el objetivo de ser superados en el futuro. 